\title{
Sobre um modo de transmissão da matemática
}

\author{
On a mode of transmission for mathematics
}

Jurema Pureza Valente 1

1 Departamento de Ciências Sociais, Escola Nacional de Saúde Pública Fundação Oswaldo Cruz. Rua Leopoldo Bulhões 1480, 8 o andar, Rio de Janeiro, RJ 21041-210, Brasil.

\begin{abstract}
This paper reports on an experience in teaching mathematics in a graduate course in public health, intermingled with reflections and concepts. Students enrolled in such courses generally feel uneasy about learning mathematics. Without underrating the usual obstacles and even affinities in developing abstractions, the results suggest that a major portion of the difficulties derives not from mathematics itself, but from an oppressive experience in the past. Difficulties also relate to the construction of space in the classroom. Such a perspective involves understanding experiments and life experiences in which the subjects are involved. In short, the work focuses on how to transmit mathematics in the development of a pedagogical approach.
\end{abstract}

Key words Graduate Education; Teaching; Mathematics

Resumo Relato de uma experiência com o ensino da matemática em curso de pós-graduação de Saúde Pública, entremeado com reflexões e conceitos. Os alunos que chegam a estes cursos sofrem, em geral, de mal-estar com a matemática. Um mal-estar histórico. Em decorrência disso, apresentam dificuldade com o aprendizado dessa disciplina. Sem pretender minimizar os obstáculos usuais e mesmo as afinidades no desenvolvimento das abstrações, sugere-se que grande parte das dificuldades não são da ordem da matemática propriamente dita, mas, com freqüência, de experiência opressiva no passado, bem como da construção do espaço de sala de aula. Tal ponto de vista envolve o entendimento da experimentação, das vivências, em que os sujeitos estão implicados. O foco deste trabalho está no modo de transmissão, no desenvolvimento de uma pedagogia.

Palavras-chave Educação de Pós-Graduação; Ensino; Matemática 
Pode-se afirmar, sem riscos de grandes incorreções, que é comum, entre estudantes, a dificuldade na apreensão de conceitos matemáticos ou, o que é quase o mesmo, considerarem que a matemática é um amontoado de fórmulas complicadas desprovidas de sentido, um mundo de aridez. Alguns falam de aptidão, talento para o pensamento abstrato, coisas dadas desde sempre. Existem os dons e há também a capacidade do aprendizado. Curiosamente, a etimologia da palavra matemática é "aquilo que é aprendido".

A intenção aqui é compartilhar fragmentos de uma experiência adquirida com o ensino da matemática nos cursos de pós-graduação da Escola Nacional de Saúde Pública da Fundação Oswaldo Cruz, entremeados com "pérolas pescadas" ao longo do tempo, buscando uni-los por um fio condutor reflexivo. Fio tênue, esboço de uma investigação.

É comum o mal-estar com a matemática sentido pelos alunos que chegam a estes cursos, seja pelo desuso, dada a profissão que escolheram - ou pior -, seja por esta escolha ter sido influenciada pela ausência desta disciplina tanto na seleção quanto no curso universitário. Isto é, se fugiram da matemática, a reencontram como exigência. Chegam com apreensão, sentem algo como uma condenação ao fracasso; supõem, por antecipação, que perderão o mestrado.

Anteriores à possível complexidade dos conceitos ou das dificuldades individuais, existem obstáculos que não são da matemática em si, mas de vivência, no passado, feita de opressão e mistério. As ditas ciências "exatas" são identificadas a camisa-de-força; há confusão entre rigor e rigidez. "Uma fala estrangeira", disse um aluno. Intimidados, a recordação da massacrante experiência com a matemática reduz-se a muitas contas e inúmeras fórmulas surgidas como cartas tiradas da manga. Desprezam-na e/ou a consideram inatingível e, nestes casos, o desprezo volta-se contra si próprios. Sentem uma deficiência e quase se envergonham por não saberem algo que "deveriam saber”. Mesmo que estes sentimentos tenham realidade, mesmo que o contato com a matemática tenha sido, de fato, precário, compactuar com a cobrança de "ter que saber" é inútil. E esta cobrança constitui também um obstáculo, é atitude improdutiva, seja porque é aprisionadora, seja porque faz barreira para que o verdadeiro problema, a ausência de entendimento, seja enfrentado.

Uma das lembranças incômodas mais freqüentes contadas pelos alunos é a cena dos muitos quadros escritos e tantas vezes apaga- dos; em curto espaço de tempo, como que envoltos em nuvem de giz. Os professores de matemática e suas abstrações falam com ninguém além de si e, em um período de aula, passamse séculos de descobrimentos e invenções, de desenvolvimento de um poderoso saber comprimido em incompreensíveis demonstrações. Dentre aqueles que conhecem alguma fluência nesta linguagem, alguns parecem relatar bom contato afetivo com os professores na origem dos tempos escolares. Estes estão ávidos, curiosos.

Aqui pretende-se sugerir que grande parte do impedimento do aprendizado da matemática está além (ou aquém) da matemática - é, também, da ordem da construção do espaço do discurso pedagógico, espaço relacional. Melhor dizendo, o espaço do discurso pedagógico deve ser um lugar onde o aluno possua existência, o que quer dizer pertinência; quando então poderá ser visto, com seus desejos e necessidades de aprendizagem, naquilo que o impulsiona e comove. Aparentemente, isto é óbvio.

O espaço da sala de aula é decerto espaço teatral. No meio artístico fazem-se discriminações quanto ao modo de fazer teatro, a respeito da existência ou não da quarta parede, aquela que separaria atores e platéia. A ausência da quarta parede implica a sustentação de certo trânsito entre atores e a platéia, a improvisação sobre um roteiro que não é fixo rigidamente, mas que permite e abre caminho para a construção de diálogos no instante, no presente, em uma disposição, em princípio, para ver e ouvir. Dito de outra forma, na sala de aula tal atitude envolve a geração de um campo relacional, onde a tensão é dada mais pelo conteúdo a ser enfrentado e menos por coisas tais como intimidação, temores ou estímulo à competição. Em tal campo relacional, visto como espaço teatral, o foco de luz está mais dirigido para o percurso do pensamento do aluno do que para a exposição do professor, pois cada aluno, em sua história com a matemática, experimentou um percurso próprio, singular, com ou sem distorção dos conceitos. Ao privilegiar singularidades, evita-se a instalação de um discurso com qualidade uniforme, supondo igualdade inexistente.

Considerando que este diagnóstico tenha realidade, ou seja, que os problemas com a matemática nem sempre são com a matemática, assim como se apresenta, a transmissão dos conceitos em curso breve e de pós-graduação exige uma modalidade de ensino que enfatize: a explicitação do que comumente diz-se ser básico e seus porquês, para transformar o fundamental naquilo que, na ordenação escolar, 
são os pilares de um pensamento, sem o qual o sentido não se manifesta. O básico, neste sentido, é então essencial, fundamental. A desconstrução do que foi absorvido mecanicamente, o afrouxamento de uma visão instalada, em especial, da crença em uma hierarquização de níveis de conhecimento e de ter que saber. Abrir uma disponibilidade para o delineamento da dúvida e para a explicitação do "não sei".

A transmissão de conhecimento, ao envolver o outro neste processo, pressupõe uma atitude ativa do aluno; em conseqüência, uma receptividade do docente. Há que se descobrir um ritmo e segui-lo, tanto quanto possível, propondo outros gestos, como em uma dança de dois. Alguma harmonia tem que se instalar, alguma sintonia, coisas do espaço do sensível. Nesta vivência, os conceitos ganham uma densidade que é distinta do entendimento puramente intelectual, ganham corpo, deixando de ser extratos externos, "fala estrangeira”. É como um aprendizado do pensar por imagens, de ver. O acompanhamento da construção do pensamento do aluno ajuda-o a discernir os obstáculos, os lugares obscuros. A dúvida, quando identificada, quase contém a sua resolução.

A tarefa, então, é a procura do auxílio necessário para a explicitação das ordenações, suas seqüências. E é nesta busca que aparecem as razões do bloqueio com o aprendizado da matemática. Com freqüência, a pressa é uma destes motivos, quando há ansiedade de tudo saber, e já. Mas a escrita matemática é sintética, concentrada, impondo um ritmo de leitura paciente. "Antes" - disse uma aluna - "é um aprendizado da humildade e de abertura para experimentar outro olhar".

Havendo lugar para errar sem julgamento e as dificuldades sendo enunciadas, as intenções ganhando forma, aos poucos a inibição é vencida, a expressão ganha entendimento, gosto, provocando sensações de alívio e gerando estímulo para que se fale esta língua, no começo tropegamente como em qualquer início.

Reforçando o já dito, a necessidade transfere para essencial aquilo que se chama conteúdo básico, e não mais importa a que nível estão localizados os empecilhos na organização curricular. Afinal, é próprio da matemática um modo de pensar. Se o obstáculo for identificado e desfeito, o que estava ressecado ganha vitalidade e impulso que anuncia o desenvolvimento do que virá. O novo, então, não é outra coisa, mas o já visto, agora, com maior abrangência, como expansão do que foi absorvido. As seqüências, ao se cumprirem pelo entendimento, freqüentemente insinuam o próximo passo.
Contudo, se a apresentação da matemática segue o tom apenas da memorização, do hábito tão típico de decorar, da absorção mecânica, o caminho da compreensão não sendo percorrido, a cada passo proliferam obstáculos, e não a percepção do percurso, do movimento. Como se em um movimento pendular, o pêndulo fosse observado apenas ao atingir os extremos e o "entre" não fosse visto, ou fosse ignorado. Ou então, é como se um habitante de um espaço tridimensional estivesse condenado a estabelecer-se em espaço bidimensional ou confinado a sua projeção, a sua sombra.

Quando se acompanha o desenvolvimento das "coisas matemáticas" de modo dialógico isto é, em relação - os conceitos vão sendo assimilados em processo interativo e as ordenações explicitadas são reconhecidas sob nova luz. A realização deste percurso, além de esvaziar a sensação de opressão gerada pelo aparente saber do outro, é terreno fértil, estruturante, nascedouro da autonomia, condição necessária a qualquer ato criativo. "Aquilo que sentimos e percebemos não é unicamente uma sensação ou uma representação, mas sim alguma coisa dotada de uma direção, um valor ou uma iminência de significação" (Paz, 1994:172).

Do ponto de vista da geometria, na convenção euclidiana, por um longo tempo, a concepção do espaço continha algo de absoluto . O espaço onde os alunos usualmente desenhavam os objetos geométricos era plano, liso, sem rugosidades, sem buracos. Mas construiu-se, ou descobriu-se - Gauss, Lobachevsky, Bolyai e Riemann, no séc. XIX - a possibilidade de fazer "geometria" com base em um conjunto de postulados diferentes daqueles da geometria Euclidiana, a possibilidade de fazer "geometria" sobre outras superfícies. Não quaisquer superfícies, pois há a exigência de "alguma regularidade”. São as ditas geometrias não-euclidianas. Apesar de desenvolvidas com base no modelo euclidiano (295 a.C.), abandona-se a concepção de verdades evidentes, responsáveis, desde os gregos, pela descrição do espaço em que se vive.

A geometria euclidiana, em seu aspecto de sistema dedutivo, foi construída sobre alicerces "universalmente reconhecidos", sobre "verdades aceitas sem demonstração"; são os chamados axiomas ou postulados, que funcionam como verdades a priori do universo. E o sistema dedutivo, um conjunto de teoremas, demonstrados com base nestes postulados, e em conceitos primitivos, como ponto, reta, plano. A partir da proposição de outros axiomas não mais se considera que exista $o$ modelo do espaço físico. Ao invés de verdades evidentes, há hi- 
póteses, consequentemente, existem muitas geometrias, mesmo com postulados que fujam à intuição.

A título de ilustração: um exemplo bastante utilizado é o da superfície esférica euclidiana como modelo para os axiomas de uma das geometrias não-euclidianas - a Riemanniana, geometria elíptica -, na qual os conceitos primitivos terão outra significação. Neste mundo, "linha reta" será substituída por "círculo máximo" da esfera; e "ponto" significará "par de pontos" diametralmente opostos.

Nestas geometrias, existe o espaço que está dado, um contínuo amorfo - no caso, as superfícies - e os objetos mergulhados no espaço. Tais sistemas tratam de descrever os deslocamento dos objetos neste mundo, observando as propriedades invariantes, por exemplo: um triângulo, após uma translação ou rotação, é um triângulo com mesmos lados e ângulos.

Mas, formaliza-se, entre o fim e o início deste século, o que já se anunciava há bastante tempo: a topologia, cujo objeto é o estudo das propriedades do espaço, esse contínuo amorfo. Propriedades isentas de qualquer idéia de medida. A topologia é popularmente chamada geometria da borracha ou, ainda, geometria sem medida. As deformações de um balão, sem furá-lo ou rasgá-lo, são exemplos de transformações topológicas. Nesta construção, em certas condições, não há distinção entre um desenho e sua cópia, mesmo que mal feita. Um círculo é topologicamente equivalente a uma elipse. Assim como há correspondência entre um rosto e seu reflexo em um espelho deformante. Ou seja “... faz-se abstração de toda idéia quantitativa e, por exemplo, se constatamos que numa linha o ponto b está entre os pontos a $e \mathrm{c}$, iremos nos contentar com essa constatação, e não nos preocuparemos em saber se a linha abc é reta ou curva, nem se o comprimento ab é igual ao comprimento bc, ou se é duas vezes maior"(Poincaré, 1995:45).Considerando este tipo de invariância, trata-se então de descrever o próprio espaço e suas propriedades: “... o espaço absoluto é um absurdo, e devemos começar por relacioná-lo a um sistema de eixos invariavelmente ligados ao nosso corpo" (Poincaré, 1995:53).

Como visto, tampouco há cisão radical entre as geometrias não-euclidianas e a euclidiana. Apesar de terem surgido da negação de um de seus postulados, comprovou-se posteriormente que a euclidiana pode ser vista como um caso particular das outras. Assim como os números inteiros relativos - surgidos de operações com os números naturais - os contêm. Esta modalidade de construção é bem típica da matemática. Ou seja, em determinado mundo - na aritmética, os números; na geometria, as formas -, com certo movimento - na aritmética, as operações; na geometria, as rotações e translações - e com propriedades específicas, se a mobilidade entre os habitantes deste mundo restringe-se, gera-se outro, onde tal movimento seja possível. É bastante comum que este outro mundo contenha o anterior que o gerou.

Evidentemente, para um entendimento destas outras convenções é necessário ir às fontes. Aqui, esta abordagem tem a função apenas de apresentação de algo típico da matemática, uma variação de significados em direção a níveis ampliados de abstração, dando a este pensamento estatuto de liberdade. Como diz a célebre frase de Cantor: “... a essência da matemática está na sua liberdade" (Davis \& Hersh, 1986:450).

Na história que os livros contam, o estudo do espaço, chamando-se "geo-metria", significava originalmente o que a palavra sugere. Isto porventura não contenha toda a verdade, as figuras geométricas e inclusive os sólidos platônicos talvez sejam idealizações ou cristalizações de formas compreensíveis de movimento, e a origem da geometria distinta, ou mais abrangente, do que a medição de terras. Poincaré (1985:78) diz: “... a geometria (euclidiana) não é verdadeira, ela é vantajosa”, pois "nossas experiências tiveram como objeto nosso próprio corpo e suas relações com os objetos vizinhos".

Quanto ao sistema numérico decimal, dizse que surgiu da associação com o número de dedos das mãos, mas, nas origens gregas, encontra-se referência à adoração que os pitagóricos tinham pelo número dez. A máxima pitagórica é bem conhecida - tudo é número. E o dez, considerado o mais sagrado, representava o número do universo, por ser a soma de todas as possíveis dimensões geométricas, pois: "Um ponto gera as dimensões, dois pontos determinam uma reta de dimensão um, três pontos não alinhados determinam um triângulo com área de dimensão dois, e quatro pontos não coplanares determinam um tetraedro com volume de dimensão três; a soma dos números que representam todas as dimensões é portanto, o adorado número dez" (Boyer, 1974:39).

Do ponto de vista da aritmética, pode ser banal o uso das quatro operações. Mas há um ganho na mobilidade do pensamento quando um aluno, independente do estágio em que esteja de seu desenvolvimento acadêmico, compreende que a subtração desfaz o que a adição faz. E a divisão, desfazendo o que faz a multiplicação, que é uma soma, é um tipo de subtração. À pergunta sobre a divisão do número dez 
pelo número dois, por exemplo, obtém-se imediatamente resposta cinco, mas não acontece o mesmo com a pergunta: por que? Afinal, diminuindo dois de dez resulta em oito, oito menos dois é seis, seis menos dois é quatro, e assim sucessivamente até chegar em zero. Este processo se completará em cinco etapas!

É comum o estranhamento com a operação de divisão, ou a divisão é "menos sensível" do que a operação de adição. O fato de a adição ser "mais natural" parece real, mas, em geral, passou-se, nos primeiros anos escolares, por cima destes encadeamentos, que tornariam a divisão, sendo o que é, mais assimilável. De outra forma, o aluno fica impedido de perceber algo igualmente essencial da matemática, ou seja, seus encadeamentos relacionais e os mundos que tais ligações geram. Sem a aquisição de certa intimidade com o seu alfabeto, as construções mais exigentes tornam-se só complexidades. Além disso, estará impedido também o acesso à simplicidade da linguagem matemática, que será formalizada na álgebra.

O nascimento da álgebra é considerado por alguns matemáticos como uma grandiosa aquisição do pensamento, pela sua potência generalizadora. Mas, não sendo compreendida "por dentro”, torna-se "receituário” e, pior, deixará de ter a função de servir como alavanca para alcançar desenvolvimentos mais elaborados.

Na resolução de equações, por exemplo: qual é o número que somado a um resulta em três? Em geral a resposta é: "pula-se o sinal de igual com o sinal trocado”. No exemplo, o um "pularia" o sinal de igual e se transformaria em menos um, sendo diminuído de três, resultando no número dois. De fato esta é a receita, e é certeira; é assim que se faz. Por que? Em geral a resposta é a de que é uma regra da álgebra a ser decorada. Mas este fazer decorado também "pula" o entendimento. O percurso do pensamento, não sendo seguido, deixa de ensinar, neste exemplo, algo primordial da história da invenção dos números, uma forma de movimento: a de ir e vir. Assim como impede a possibilidade da compreensão de que movimentos iguais em ambos os lados de uma igualdade a conservam, ou, como dito usualmente, a igualdade não se altera.

Então, havendo um movimento - no caso, uma soma - segue-se a pergunta a respeito do movimento que a desfaz. No exemplo, a igualdade não se altera, desfazendo a ação de somar um em cada lado. De um lado da igualdade, as ações anulam-se por serem opostas; a incógnita agora está isolada. De outro lado, a operação a responde, e nenhum número "pulou" de um lado para o outro nem sumiu de um lado da igualdade para aparecer do outro. A percepção/entendimento de inversões é uma das fontes nutridoras da mobilidade do pensamento, mais do que a destreza na resolução de equações. Além de ser semente, pois, dado um espaço ou conjunto, a pergunta acerca da existência de inversões aí, segundo alguma operação ou movimento, estará presente nos diversos estágios do desenvolvimento da matemática.

Pelo menos do ponto de vista de uma das escolas formadoras do pensamento matemático, é assim que se origina a elaboração da história da invenção dos números que manipulamos, e a matemática, um estudo de estrutura de relações, conforme descreve Dieudonné (1990: 118): "Pouco a pouco, desenha-se uma idéia geral que será precisada no séc. $X X$, a de estrutura na base de uma teoria matemática; é a constatação de que aquilo que desempenha o papel primordial numa teoria são as relações entre os objetos, e que, em duas teorias diferentes, pode acontecer que haja relações que se exprimem da mesma maneira nas duas teorias; o sistema destas relações e as suas 'correspondências' é uma mesma estrutura 'subjacente' às duas teorias”.

Estrutura significa: um conjunto de objetos, operações ou relações definidas freqüentemente com um conjunto de objetos especiais ou distinguidos. Um exemplo: os objetos, sendo números pertencentes ao conjunto dos reais, e um conjunto de axiomas que definirão as operações soma e multiplicação, os elementos distinguidos são o zero e o um. São os elementos neutros para a soma e para a multiplicação, respectivamente, e eles possibilitam, neste mundo, inversões. Assim, uma estrutura matemática poderá ser erguida por este tripé.

Então a formulação do conceito de relação é pilar. Será que desempenha atualmente algo análogo ao que significava a forma triangular, com suas propriedades, para os gregos?

Diz Poincaré (1995:22): "Provavelmente já viram esses conjuntos delicados de espinhas siliciosas que formam os esqueletos de certas esponjas. Quando desaparece a matéria orgânica, só resta uma frágil e elegante renda. É verdade que ali não há só silício, mas o que é interessante é a forma que esse silício tomou, e não podemos entendê-la se não conhecemos a esponja viva que precisamente lhe imprimiu essa forma. $E$ assim que as antigas noções intuitivas de nossos antepassados, mesmo que já abandonadas, ainda imprimem sua forma às construções lógicas que colocamos em seu lugar".

A rigor, a concepção do conceito de relação, na história que os livros contam, remonta aos tempos em que tampouco existia a noção de número, quando o cuidador de rebanhos infor- 
mava-se dos nascimentos e das mortes caso faltassem ou sobrassem pedrinhas, em processo de correspondência um-a-um entre animais e pedrinhas.

Assim, para falar de relação há que existir uma trama, uma teia, uma rede, e se esta trama não está dada, há que tecer este tecido, para então aí construir ou descrever o bordado. $\mathrm{O}$ bordado não precisa ocupar todo o tecido, pode ser um percurso, pode ser pontuações.

Para definir matematicamente uma relação, necessita-se de uma "certa tríade", ou seja, há a exigência de um primeiro conjunto (ou pertinências) e de um segundo conjunto (que pode ser o mesmo); gera-se então um novo conjunto feito do cruzamento deles, a trama. Os habitantes deste novo conjunto são pares ordenados, o primeiro elemento do par pertence ao primeiro conjunto, o segundo ao segundo. Uma relação é um conjunto formado por habitantes deste tipo, pares ordenados, escolhidos por uma regra, uma lei que associa alguns (ou todos) elementos de um com os do outro conjunto. Dito de outra forma, a lei leva um elemento de um primeiro conjunto a outro elemento, agora do segundo conjunto. Desse modo, a lei é um transportador, e a trama, um produto de conjuntos, um novo espaço gerado pelo cruzamento dos fios. A dimensão deste novo espaço é a soma das dimensões dos espaços que o geraram. Esta construção parte da existência de conjuntos, isto é, de pertinências, pois falar de conjuntos é falar de quem os habita. Tais conjuntos podem ser representados por eixos, que são referências, como os eixos cartesianos que geram o plano cartesiano. Quando os conjuntos são numéricos, um ponto neste espaço é um par de números, distâncias relativas ao eixos, portanto, este espaço tem dimensão dois. Assim como a reta é um espaço de dimensão um, pois basta uma distância para localizar um ponto, relativo a uma origem dada. Um ponto em espaço tridimensional, isto é, em espaço gerado por três eixos ortogonais entre si, é um terno ordenado. E assim sucessivamente pode-se construir espaços de quaisquer dimensão, mesmo sem a possibilidade de representação geométrica.

Graficamente, uma relação é um desenho, uma curva ou uma área no plano cartesiano, a representação de uma variação concomitante. Tem a forma de um círculo, por exemplo, sendo os eixos numéricos, da regra ou lei: "a soma do quadrado de dois números é constante”. Ou uma parábola, quando uma seqüência numérica cresce segundo o quadrado dos números.

Do ponto de vista da matemática, função é um tipo ou um caso especial de relação. Ou se- ja, a função é definida como uma relação com restrições, de forma a evitar ambigüidades.

Em algumas abordagens, o número é visto como nascido de uma relação, sendo uma lei, talvez a mais simples, que traduz aquilo que há de comum ao associar-se carneiros e pedrinhas, criando a partir destes conjuntos, uma superentidade que, então, por um processo de correspondência, os torna único.

Dentre os matemáticos que fundaram escolas, distinguem-se, pelo menos, dois tipos de espíritos: uns, mais guiados pela lógica; outros, pela intuição. Os primeiros tendem a ser analistas, os outros mais geômetras. Diferem, segundo Poincaré (1995), pela necessidade de apoiar-se ou não em “bastão mais sólido”. Para os logicistas, a matemática e a lógica são indistinguíveis. Outros consideram-na como a higiene da matemática, mas não a sua fonte de alimento (Boyer, 1974).

Talvez a educação matemática sofra de um tipo de rigidez herdada, no dizer de Poincaré (1995:20): “...ao se tornar rigorosa, a ciência matemática assume um caráter artificial”. Suas fórmulas soam misteriosas e tornam-se restritivas, se apreendidas estritamente pelo intelecto, quando estão desvinculadas das outras dimensões da experiência da vida, como a capacidade de sentir, mesmo sabendo-se que os sentidos também podem ser fonte de enganos. Segundo Otte (1993:15): “A observação é suscetível a muitos enganos, sobretudo quando não se tem a possibilidade de mudar de posição. Ver exige movimento, porque a mera observação precisa das diferenças causadas pelo movimento".

O texto matemático é direto, simples e sem ambigüidade. Quando se diz “ $x$ ”, isto significa " $x$ ". Mas a rigidez manifesta-se caso a matemática seja concebida como fundamentada sobre alicerces "firmes e definitivos", apesar da existência dos paradoxos e da história das deduções (Costa, 1992). As inspirações que resultaram e resultam em descoberta ou em invenção, as exatidões, devem ser de outra ordem, mais aparentadas à vertigem de que à fixidez, conforme afirmam Davis \& Hersh (1986:345): “Todos nos sentimos melhores quando nos movemos da parte analítica para a parte analógica do espectro das experiências".

Para Bergson, “... a capacidade da inteligência é simplesmente a capacidade da medi$d a$ " (Bergson, 1912, apud Mora, 1986:318). Afinal, a medida das coisas não são as coisas, apesar das percepções inequívocas dos gestos com justa medida. Melhor dizendo, o problema não é a medição, mas os excessos de sua utilização, em especial, quando isto se estabelece com estatuto de certeza. Stewart (1996: 
112) diz que o "quantitativo é apenas um qualitativo pobre".

Qualquer tipo de ordenação mecânica, rígida, é como uma fonte de traição à vida, que se organiza pelo movimento e pela fluidez. Talvez seja premente uma outra razão científica, outra educação escolar que não priorize a "razão pura" em detrimento das "emoções”. Uma razão surgida das vivências, dos pensamentos e das ações do cotidiano. Lembra-nos Reich (1949: 132) que: "É o organismo vivo que ordena, reagrupa e conecta suas sensações antes de articulá-las em fórmulas matemáticas".

E Octavio Paz enuncia o desejo de que surja um "Kant” que faça a crítica da razão científica:

“Depois das orgias intelectuais deste século é preciso desconfiar da história e aprender a pensar com sobriedade. Exercício de desnudamento; jogar fora os disfarces, arrancar as máscaras. O que ocultam? O rosto do presente? Não, o presente não tem cara. Nossa tarefa é justamente dar-lhe uma cara. O presente é uma matéria ao mesmo tempo maleável e indócil-parece obedecer à mão que o esculpe e o resultado é sempre diferente do que imaginávamos. É preciso resignar-se, pois não temos outro recurso: pelo mero fato de estarmos vivos, temos de enfrentar o presente e formar um rosto dessa confusão de

\section{Agradecimentos}

A Luis David Castiel pelas correções e sugestões criativas em uma primeira ordenação deste trabalho.

\section{Referências}

BOYER, C. B., 1968. História da Matemática. São Paulo: Editora Edgard Blücher.

COSTA, N. C. A., 1992. Introdução aos Fundamentos da Matemática. São Paulo: Editora Hucitec.

DAVIS, P. J. \& HERSH, R., 1986. A Experiência Matemática. Rio de Janeiro: Francisco Alves Editora.

DIEUDONNÉ, J., 1990. A Formação da Matemática Contemporânea. Lisboa: Publicações Dom Quixote.

GORMAN, P., 1979. Pitágoras: Uma Vida. São Paulo: Pensamento.

MORA, F., 1986. Diccionario de Filosofía. Madrid: Alianza. linhas e volumes. Converter o presente em presença. Por isso a pergunta sobre o lugar do amor no mundo atual é, ao mesmo tempo, iniludivel e crucial. Escamoteá-la, é mais que uma deserção, uma mutilação" (Paz, 1994:141).

Tales de Mileto, um dos primeiros matemáticos gregos (VI séc. a.C.), insistia no "como"; “o mais fundamental não é o que sabemos, mas como o sabemos" (Boyer, 1968:33). Para seu contemporâneo pré-socrático, Pitágoras, e para a escola pitagórica, exercitar-se em matemática era exercitar o espírito; “...os sentidos eram o ponto de partida para atingir o conhecimento de realidades que transcendiam os próprios sentidos" (Gorman, 1979:183). As "coisas matemáticas", intermediárias entre o mundo sensível e o inteligível (Mora, 1986:1595).

A estética matemática, por não gostar das ambigüidades, busca entidades num plano mais abrangente, que as superem, indo além. Se os seus objetos com suas propriedades possuem existência real ou não, decidir se estão ou não fora da mente humana, é ainda atividade humana. Esta estética manifesta-se também como uma linguagem que busca a explicitação de ordens internas, as analogias íntimas entre as coisas, a expressão das harmonias, dos ritmos e suas relações. São percursos. A matemática "liga" as coisas, disse um aluno.
OTTE, M., 1993. O Formal, o Social e o Subjetivo: Uma Introdução à Filosofia e à Didática da Matemática. São Paulo: Editora da UNESP.

PAZ, O., 1994. A Dupla Chama: Amor e Erotismo. São Paulo: Siciliano.

POINCARÉ, H., 1985. A Ciência e a Hipótese. Brasília: Editora da Universidade de Brasília.

POINCARÉ, H., 1995. O Valor da Ciência. Rio de Janeiro: Contraponto.

REICH, W., 1949. L'Éter, Dieu et le Diable. Paris: Payot. STEWART, I., 1996. Os Números da Natureza. Rio de Janeiro: Rocco. 